\title{
The Marginalisation of the Gamo Ethnic Group through Curriculum Planning and Processes in Ethiopia
}

\author{
Yishak, DM \\ University of South Africa \\ 47016787@mylife.unisa.ac.za \\ Gumbo, MT \\ University of South Africa \\ gumbomt@unisa.ac.za
}

Doi:10.5901/mjss.2014.v5n10p285

\begin{abstract}
In Ethiopia the indigenisation of the basic education curricula from an ethnic group perspective was introduced in the post 1991 era following the onset of a new kind of political order known as ethnic federalism. The purpose of this paper is thus to critically analyse the indigenisation of curriculum planning and implementation processes of the basic education curricula from the Gamo ethnic group's perspective. The study used a qualitative multiple case study approach and design. Two cases from the Gamo Gofa Zone (GGZ) and the Addis Ababa City Administration (AACA), were treated similarly to study the basic education curriculum planning and implementation process. The findings of the study disclosed that the indigenisation of curriculum from the Gamo ethnic group's perspective has some strength, but there are also major deficiencies. In order to further build on the strengths and resolve the deficiencies, a stand-alone indigenisation approach has been suggested, which proposes that the curriculum be based on indigenous foundations, theories, principles and ideas derived from the culture. Thereafter, a blending approach should be considered, which allows for intercultural dialogue.
\end{abstract}

Keywords: indigeneity, ethnicity, basic education, relevant education, curriculum, socio-cultural context.

\section{Introduction}

In Ethiopia, two forms of indigenising the basic education curricula, namely, indigenisation from a national perspective (Ethiopianisation) and indigenisation from the ethnic groups' perspective (regionalisation/localisation) had been attempted so far (Yishak \& Gumbo, 2012). However, despite these attempts scholars decry the irrelevance of the curricula to the culture, history and heritage of indigenous Ethiopians (Woube, 2004; Tekeste, 2006; Roschanski, 2007; Amare, 2009a; Ministry of Education (MOE), 2010). Thus, the problem being addressed in this paper is the lack of responsiveness of the basic education curriculum to the context of the Gamo ethnic group. Our aim is thus to critically analyse the process of planning and implementing the basic education curricula for the Gamo ethnic group in rural and city settings. This study is situated within the African critical theory paradigm (Rabaka, 2009), because approaches to curriculum construction and change, as contextualised social processes, are located within this paradigm (Cornbleth, 1990; Kincheloe, 2006). In maintaining this critical stance, we first review related literature. Next we discuss the methodology of the study. Then we follow an integrated approach to present the findings. Finally, we make pertinent conclusions and recommendations.

\section{The Historical Context of Curricular Reforms in Ethiopia}

During both the Imperial and Derg regimes attempts were made to Ethiopianise the education system at primary school level, which involved changing the medium of instruction, the textbook language and the involvement of Ethiopian personnel in the process of curriculum development and implementation (Tekeste, 2006; Solomon, 2008). However, the Ethiopianisation at national level was considered an affirmation of the assimilation policy and publicly opposed by the subjugated ethnic groups, which led to the formation of ethnic movements and armed revolts in the empire-state (Teklehaimanot, 1999; Kassam, 2002; Habtu, 2003).

Ethnic federalism was introduced in Ethiopia in the post 1991 era (Habtu, 2003; Tekeste, 2006; \& Lovise, 2011), marking the beginning of indigenisation from the ethnic groups' perspective (Tekeste, 2006; Yishak \& Gumbo, 2012). 
Girma (2012) identified similarities between this ethno-federalist approach to education and the postmodernist way of thinking in that both make ethnic minority the centre of their moral discourse.

\subsection{Determinants of education's and curriculum's relevance}

Educational relevance is dictated by relevant and functional curriculum and pedagogy extracted from the culture of the people (Salia-Bao, 1989; Dei, 2008). The relevance and functionality of the curriculum is, in turn, dictated by its relation to the culture, livelihoods, value schemes and psychological make-up of the society (Amare, 2009b); its rootedness in the culture, environment and needs of the people; its grounding in the philosophy, politics and economy of the society (Salia$\mathrm{BaO}, 1989$ ); and its alignment to the social structure to which the students belong (Shiundu \& Omulando, 1992). Cornbleth (1990) has come up with a notion known as curriculum in context, which concurs with critical complex epistemology stated by Kincheloe (2008), that advocates the inseparable link between knowledge and context. Shizha (2006) and Sleeter (2005) similarly explicate that knowledge is a product of people's socio-cultural milieu.

An antithesis to the curriculum-in-context approach is the standardisation of the curriculum, which advocates a "one-size-fits-all" approach. The standardisation approach is non-responsive to the learners' context and delinks school education with their lived experiences leading those from marginalised backgrounds to high levels of educational failure (UNESCO, 2009). Therefore, the indigenisation approach is a favourable approach as a revolution for relevance for curriculum studies and development, to ensure its relevance to the group it is intended to serve. These raised issues have sparked an indigenisation discourse about the curriculum. It is in this context that curriculum development and studies have begun to use indigenisation as a strategy to rehabilitate the knowledge-base and perspective of the subjugated indigenous peoples and incorporate concepts derived from indigenous knowledge (Ismailova, 2004).

The discourse on indigenisation from the Social Work perspective criticises professional imperialism, questions western values and theories, emphasises the importance of the indigenous social and cultural structure and stresses the irrelevance of western theories and approaches developed in the metropolitan states of the western world in non-western contexts (Tomaselli \& Shepperson, 1999; Yunong \& Xiong, 2008; \& Gray, 2010). The failure of the indigenisation approach to change the original model's ingrained philosophy from the interventions in the recipient nations, compelled the latter to generate the authentisation or culturally appropriate approach, which looks for the authentic roots in the local system to construct a domestic model in the light of the socio-cultural context (Walton, \& Abo El Nasr, 1988; Ferguson, 2005).

In the field of psychology indigenisation is seen as a process of making knowledge culturally appropriate by transforming the transplanted or borrowed external elements to make them suit the local context (Sinha, 1997). As elsewhere, the "indigenisation from without" approach has failed in the Philippines leading to the adoption of another version of indigenisation, known as "indigenisation from within" or cultural revalidation (Pe-Pua, 2006). Therefore, we argue that for indigenisation from without to materialise indigenisation from within should be carried out first. This is due to the fact that unless the key cultural constructs are well identified, using "indigenisation from within", it will be difficult to carry out the "indigenisation from without" project. We also want to draw into this discourse different genres of the indigenisation approach.

In general, the approaches to indigenisation can be broadly categorised into three, namely, a complete break from western knowledge, blending western knowledge and indigenous knowledge, and restructuring or adapting the borrowed or inherited western knowledge. Blyden (1969) advocates a complete cultural separation from the west in order to preserve and develop local traditions. Blyden (1969) indicates that Africa used to live in peace until its contact with Europeans; thus, the only means to regain the lost innocence and peace in Africa is to return to its original traditions and to restore its own institutions. On the other hand, researchers and political figures in Africa suggest the blending of the positive aspects of indigenous knowledge with carefully selected and imported Western science and technology in a democratic and self-determined way (Salia-Bao, 1989; Tedla, 1992, 1995; Mkapa, 2004; Shibanda, 2006; Shizha, 2006). Yet another suggestion involves only restructuring or adapting the borrowed or inherited Western methods to make them suitable to the context. This approach reduces the marginalised groups to the level of consumers of knowledge produced elsewhere, rather than producers of their own knowledge (Hawi, 2005).

We argue that a complete separation might further marginalise subordinate groups by denying learning from what others have achieved. Our argument is informed by the fact that the closed-door policy pursued by the Ethiopian Emperor Fasiledes (reign 1632-1667) barred all Europeans from entry into the Christian highlands. This policy kept Ethiopia isolated from the rest of the world for two centuries (Marcus, 1994) and blocked the opportunity to learn from others and, thereby, hampered Ethiopia's development. Vilakazi (1999) similarly argues against the complete break approach, which would imply that Africa be closed off to outside influences, since no civilisation has ever developed and prospered in 
isolation.

Restructuring or adapting the borrowed or inherited western methods has also failed in the global south and this has led to the suggestion of an alternative approach. Even if the content of the subjects started being African, the western cultural influences embedded in the foundations are still being transmitted to the students (Salia-Bao, 1989). The new approach, thus proposed, is known as "indigenisation from within", cultural revalidation or authentisation (Walton, \& Abo El Nasr, 1988; Messay, 2004; Ferguson, 2005; \& Pe-Pua, 2006). The blended approach is flawed in that its proponents are unable to anticipate its feasibility. The western world and marginalised people have different philosophies of life and education. In addition, the knowledge of the marginalised people is underdeveloped, because of the onslaught from the western knowledge and, thus, whenever we try to blend them, there is a likelihood that the former will rise above the latter. How can one blend two substances with different characteristics and textures? Indigenous knowledge should thus be allowed to thrive, before any consideration is made to blend it with western science and technology (Yishak \& Gumbo, 2012).

Language, multicultural education and a culturally-relevant pedagogy have a direct bearing on the indigenisation approach. Therefore, it is imperative to take a brief look at them.

\subsection{The role of language, multiculturalism and pedagogy in indigenisation approach}

Language is an important component, which serves as a mirror of ethnicity and culture (Banks, 2006; Shizha, 2007; Janetius, Bekele \& Mini, 2008), a medium through which the content of ethnicity, culture and the identity of a group is formed and transmitted (Banks, 2006), and a vehicle in the formation of the offspring's perceptions, attitudes and values about their physical and social environment (Shizha, 2005; Banks, 2006). Therefore, as Shizha (2007) asserts, language is a vital component for incorporating indigenous knowledge and culture into the school curriculum. Thus, the indigenisation approach needs its languages in order to materialise.

Multicultural education fosters an equal chance for academic achievement for all students by readdressing the racial and structural inequalities embedded in mainstream education (Gumbo, 2001; Banks, 2006; Banks \& Banks, 2010; \& Bennett, 2011). Banks and Banks (2010:4) and Banks (2006:4) identified five dimensions of multicultural education, namely: content integration, the knowledge construction process, prejudice reduction, equity pedagogy and empowering school culture and social structure. According to Bennett (2011), multicultural curriculum is devoted to the incorporation of content, which builds a sense of ethnic pride within each student, to cater for multiple historical perspectives of diverse ethnic groups and to eliminate distortions, stereotypes and serious omissions of the ethnic minorities' perspectives harboured in the mainstream-centric curriculum.

Culturally relevant pedagogy aims at embedding students in their community and culture by intentionally connecting teaching to their lived experiences and knowledge-frameworks communities (De Lissovoy, 2008). The crux of a culturally relevant pedagogy is the validation and affirmation of the cultural knowledge, prior experiences, frames of reference and performance styles of ethnically diverse students (Gay, 2000). Culturally relevant pedagogues could be produced by re-orienting prospective teachers with their own and others' culture and the role of culture in education (Ladson-Billings, 1995).

\section{Research Design and Methodology}

This study used a qualitative case study approach and design. Both a case study and a qualitative study investigate a contemporary phenomenon within a real-life context (Denzin, \& Lincoln, 2005; Yin, 2009). Thus, indigenising the basic education curricula from the Gamo ethnic group's perspective could be comprehensively studied using a qualitative case study design.

More than eighty ethnic groups were listed in the 2007 census in Ethiopia. Only ten of them had a population of one million or more. Gamo is the tenth of these ethnic groups with a total population of 1107163 and accounts for 1.5\% of the total population of Ethiopia (CSA, 2008). Today members of the Gamo ethnic group reside both in the GGZ, which is their homeland, and the capital, AACA. Thus, these two settings were selected as most suitable for the separate research cases, that is, Case 1 and Case 2, respectively, using purposeful sampling (Creswell, 2009).

Yin (2009) suggests three sources of evidence, namely, in-depth interviews, observation and document analysis, which were considered in this study. Six curriculum experts from these two settings were selected by means of snowball sampling to easily locate information-rich key informants (Patton, 2002). Two schools from each setting were selected through purposeful sampling (Creswell, 2009). Three teachers and two principals were selected for interviews from each school using purposeful sampling (Creswell, 2009). Three learners' parents were selected from each school using 
snowball sampling (Patton, 2002). Data gathering was conducted from 1 June to 16 July 2013.

A theory-based qualitative analysis was used (Patton, 2002). Data were analysed based on the critical theory of different genres such as multicultural theory, cultural relevant pedagogy, African critical theory and critical pedagogy - not to deny the voices of the participants their liberty of expression (Guba \& Lincoln, 1994). Themes under which findings are presented were developed using relevant coding and categorisation.

Respecting the anonymity of the participants is one of the ethical principles in research (Bogdan \& Biklen, 2007). To ensure this principle is adhered to, simple codes were used to denote individuals who participated in the research. The codes were prepared by merging letters and numbers as follows: C1 stands for Case 1 (GGZ) and C2 for Case 2 (AACA). T stands for Teachers, D for Directors, E for Experts and P for Parents.

\section{Findings: Curriculum Planning and Implementation}

This section presents a critical within-case analysis of the data obtained from each case and the cross-case critical analysis of the two cases.

\subsection{Distinct features of the Gamo ethnic culture and value systems}

In GGZ the Gamo ethnic group has a distinct ethnic culture and unique value systems. The ethnic group has an administrative system carried out by the institution called dubusha (the assemblies). The dubushas are presided over by the political leaders called halaqas and hudugas. The mesqel feast is celebrated by all members of the ethnic group as a cultural holiday commemorating the onset of a new year.

The most important values of the Gamo ethnic group are communal life, resilience in the face of different natural hazards, a propensity to be hardworking, dislike for begging, truthfulness and respect for women and elderly people. The following quotation serves to illustrate the dislike for begging:

The Gamo ethnic group participated in the construction of a road from the town of Chencha up to Zozo. On the completion of the construction of the road the then Relief and Rehabilitation Commission brought wheat as food aid to the people. However, the people told the Relief and Rehabilitation Commission that they should send the food to other famished people. 'We do not want your relief and we do not need any kind of support (C1D2).

The staple diet of the GGZ Gamo people mostly include a fruit similar to a banana, called enset, and different kinds of cereals. The Gamos have a traditional food called shendera and qinche, which are different kinds of porridge made of flour, milk, yeast and butter. The AACA Gamos prepare different kinds of foods such as kashka, fetela, uketsa and moydee (porridge) from maize and wheat flour. They also use enset products like unchaa and bulaa. They have a special drink known as borde, made from wheat flour. In the city, weaving is the main means of earning a living for members of the Gamo ethnic group. Both the GGZ and AACA Gamos make fine embroidered material known as tibeb, kuta, netella, qamis, gabi, buluko and dunguza.

The Gamo ethnic group has its own mourning ceremony where the deceased person is praised through songs and dances. The mourners wear and carry the skins of a lion and a leopard, ostrich feathers and spears. The Gamo wedding ceremony is arranged through a mediation process overseen by the elders, known as lazantse. If a man wants to be married to someone, he sends his family representatives to the parents of his fiancée to being the negotiations. The elders, sent for mediation, will be allowed to enter the house of the girl's parents on their third trip and fix the date of marriage together. Close similarities surfaced from the findings between the GGZ and "uneducated" AACA Gamos in this regard. For instance, the mourning ceremony of the AACA Gamos involves traditional singing and dancing in the vernacular language. The mourning ceremony is conducted pretty much the same as in GGZ. A participant, C2D1, who happened to be an Amhara, explained the mourning ceremony as follows:

When I saw the mourning ceremony for the first time it was unique to me. ...but here among the Gamo ethnic group there is a clapping of hands and special traditional dances. The mourning ceremony of the Gamo ethnic group has its own artistic quality. There are people who hold spears and shields and lead the mourning ceremony. For a person who does not know the Gamo culture and who watches the mourning ceremony for the first time, the ceremony is surprising.

The important values of the Gamo ethnic group are gome, (a misfortune which afflicts a person for the transgression of a traditional rule), respect for work, helping each other in the time of adversity through a social care programme. This social programme is known as ertsiban, which is a mechanism to resolving conflict and participation in a 
communal work called debo and jigge.

It can be gathered from the findings that different features, which denote the Gamo ethnic group, still persist in both the GGZ and AACA settings, despite attempts to discredit them in the school curriculum. In the city setting these cultural practices are strictly upheld by the "uneducated". This speak for the reality about the peculiarity of an ethnic group as defined by the literature - an ethnic group shares a common set of values, experiences, behavioural characteristics and linguistic traits. What sustains the group is history and tradition (Banks, 2006; Bennett, 2011).

\subsection{The present primary first-cycle curriculum for the Gamo ethnic group}

The deficiencies in the curriculum in GGZ were identified in the findings as well as attempts to correct the situation. According to the findings, the curriculum for the Gamo ethnic group was developed by translating the contents from the Amharic versions prepared by the Southern Nations, Nationalities and Peoples Regional (SNNPR) Education Bureau. However, the Gamotso language textbooks were prepared at GGZ by language teachers who belong to the Gamo ethnic group. The educated elites of the ethnic group decided on the use of the Gamotso language as the medium of instruction and textbook language by adopting the new script for the language.

C1E1 explained the insufficiency of a mere translation of the materials, available in Amhara language, into the Gamotso language:

What has been carried out here is the translation of the Amharic version into the Gamotso version. Whenever a direct translation takes place it is the raw word that is translated and there is no possibility of mixing cultural elements in it. Therefore, the primary first-cycle curriculum is not prepared based on our culture.

C1E2 explained the initiative that he took to resolve this situation:

I was the person who coordinated the process of preparing own materials because by then I was the head of the Zone Education Department. Such locally prepared materials reflect the Gamo culture such as its hand-weaving, patriotism, mourning and joy ceremonies. Because of this the results of the students in the Gamotso subject were very high. Though an attempt has been made this process is far from complete.

A short review of textbooks for the primary first-cycle education confirmed that the Gamotso language textbooks were prepared by the GGZ Capacity Building Co-ordination Main Department, Education Desk, while those for the rest of the subjects were prepared by translating the Amharic version prepared by the SNNPR Education Bureau. The Gamotso language textbooks better reflected the culture of the ethnic group, than textbooks for the other subjects.

Some interviewees were of the view that, to some extent, the curriculum is responsive to the culture and heritage of the Gamo ethnic group, while others viewed it as an imposition from above that did not cater for the culture and heritage of the ethnic group. C1T1 indicated this limitation in the following way:

For instance, it is silent about the initiation of halaqa, the celebration of the meskel festivity, our mode of dressing, work, and heritages... a local trumpet known as zaye which is made of animal horn. This instrument is important and should have been incorporated in the curriculum but it is not.

C1T3 supported the non-responsiveness of the curriculum to the culture and heritage of the Gamo ethnic thus:

The environmental science known as Herra Sayinsi and Mathematics textbooks are translated into Gamotso from the Amharic version....when the environmental science introduces a concept it directly translates it from the Amharic version... In environmental science there is a section where it speaks about heritages which totally refers to national heritages as a whole but not the heritages of the Gamo which show the identity of the ethnic group. It is directly copied from others, and does not cater for the culture of the Gamo.

The supporters of the view of the non-responsive curriculum, C1D1 and C1D2, put the blame on the process of curriculum preparation, which involved only the educated elites and lacked proper prior research. C1E1 also held the view that the curriculum was non-responsive to the culture, heritage and context of the ethnic group.

A significant number of interviewees indicated that the values of the Gamo ethnic group were partially reflected in the curriculum, but better reflected by the teachers in the teaching-learning process. The fact that the subjects were being taught in the Gamotso language provided a better chance that the content will reflect the Gamo ethnic group's values in the teaching-learning process. However, the most important values, such as the dislike of begging, were ignored because of the process of curriculum development, which was non-participatory and not grounded in research. 
Given the complex city environment, as confirmed by the participants, the AACA findings were characterised by diverse views of the participants. These findings revealed that the Education Bureau prepared textbooks, teachers' guides and material for radio lessons based on the curriculum framework prepared for national use by the Ministry of Education. The selection of the contents for the textbooks involved the school community. In contrast to the findings in the GGZ, C2E1 and C2T3 argued that the development of the curriculum in the Amharic language as reflecting national issues. However, C2T1 and C2T2 viewed impartiality as the reason for the incorporation of culture and heritage in the curriculum, informed by the multiethnic composition of the inhabitants of the city. C2E1 defended this approach in the following way:

The textbook drafts are prepared by the Addis Ababa City Administration Education Bureau, using the contents selected by means of community participation. The social, economic and political contexts of the ethnic groups were taken into consideration during the involvement of the stakeholders in providing their feedback on the textbook drafts. The stakeholders drawn from the different ethnic groups in the city were allowed to identify the elements omitted and the shortcomings of the draft textbooks. The textbooks were rewritten by incorporating the feedback from the stakeholders before they were dispatched to the schools.

\section{C2E2 added:}

The materials were prepared based on the curriculum framework and the guidelines, and there was no possibility to add or subtract from what had been suggested. If attempts were made to be responsive to the socio-cultural and structural context of the different ethnic groups in the city, there may be deviation from the framework and the guidelines. However, attempts have been made to reflect the culture of the ethnic groups in the subject environmental science though it is not complete and free from limitations.

A brief review of the Grade 4 Environment Sciences textbook confirmed the argument of the curriculum expert. The textbook had one chapter devoted to Ethiopian peoples, cultures, civilisations and heritages. It discussed the cultures, civilisations and heritages of the ethnic groups of Northern Ethiopia. Four pages in the book were devoted to introducing the great Northern Ethiopian thinkers, but there was no representative for the Gamo ethnic group. As a result, the interviewees confirmed that none of the specific values of the Gamo ethnic group were reflected in the curriculum of the AACA. The pretext for this is that AACA is multi-ethnic and the curriculum focuses on the so-called common national values, which are supposed to be shared by all ethnic groups alike.

The findings reveal that the curriculum of the GGZ is partially responsive to the culture and values of the ethnic group, while that of the AACA almost completely ignores the Gamo culture, language and values. As Bennett (2011) (also see Banks \& Banks, 2010; Shizha, 2006; Slattery, 2006) argued, serious omissions of the culture and values of ethnic minorities in the curriculum has been the technique used by mainstream-centric curriculum development in order to systematically maintain the dominance of the major ethnic groups. The multi-ethnic and national setting of the AACA is used as a pretext for not catering for the culture, language and heritage of the Gamo ethnic group in the curriculum. In the name of a common national culture the curriculum actually reflects the culture of the major dominant ethnic groups such as the Amhara, Tigre and Oromo. It is, therefore, unfair and unjust not to cater for the Gamo culture and heritage in the curriculum, since the majority of the learner population, where this study was conducted, is from the Gamos ethnic group.

\subsection{Responsive pedagogy for the Gamo people: identity, culture and language}

The findings under this theme revealed that the GGZ teachers adopted different strategies to make the pedagogy responsive to the learners' culture and heritage - using local examples from the ethnic group's culture; reducing prejudice and creating awareness by reminding learners that the Gamotso language is not inferior or superior to other languages; engaging learners in group debates on cultural issues; and using cultural heritages as teaching aids. A culturally relevant pedagogy helps learners to develop cultural competence in the local language and interaction styles (Ladson-Billings, 1995).

In contrast, the findings revealed that the AACA curriculum was highly prescriptive and does not let teachers use culture-responsive pedagogy. As a result the teachers were obliged to work according to the curriculum. However, in the subject Aesthetics, which integrates music, art and sport, the teachers encouraged learners to sing and dance based on their cultural heritage and traditions. Some teachers used the extra-curricular activities (specifically the music and drama clubs) to teach learners about the Gamo culture and heritage. The learners brought their traditional clothes, artefacts, cultural food, clothes and materials used in hand-weaving to school. 


\title{
4.4 Consideration of the cultural knowledge, prior experiences and performance styles of learners
}

The content of the curriculum still represents globalisation and global issues at the expense of cultural knowledge. As a result, learners are compelled to completely ignore their culture. This was evident from the findings in Case 2 (AACA). The approach to the curriculum and medium of instruction showed a disconnection between learners' prior experiences and the teaching-learning situation. Though the teachers made an effort to base the teaching-learning process on the experiences learners brought from home, learners from the dominant ethnic groups ended up benefiting, because the curriculum is more directly aligned to their home environment. Most of the teachers in the school belonged to the Gamo ethnic group; thus, it was easier for them to communicate with and support their learners. But these very same teachers argued that they could not help the learners in the Gamotso language at school, because the curriculum did not allow the use of the ethnic groups' languages as the medium of instruction and in school-wide communication.

However, the GGZ teachers used their own initiative to prepare products that reflected the culture and customs of learners. The teachers also tried to relate the lessons to the learners' prior experiences. They invited learners' experiences by asking questions and anchoring the lessons on these experiences. The schools' pedagogical centres prepared different teaching aid materials used by the teachers to address the different learning styles. The teachers' views and a review of learners' results revealed that the Gamotso language subject considers learners' cultural knowledge and prior experiences in a much better way. This approach helped to give primacy to the incorporation of contents, which built in each learner a sense of ethnic pride (Bennett, 2011). As a result learners' motivation to learn and their results in subjects offered in the local language were high.

\subsection{Indicators of the link between school knowledge and the local culture}

Learners from the GGZ learnt better when they are taught in their home language and they obtained better results. This is because the subjects given in the Gamotso language were easier for learners to understand. Banks and Banks (2010) state that learners learn best and become highly motivated when the school curriculum is developed based on their cultures, experiences and perspectives. Academic knowledge and skills are more likely to be personally meaningful, have higher interest appeal, learnt more easily and thoroughly and could lead to high academic achievement, if delivered using culturally relevant pedagogy (Ladson-Billings, 1995; Gay, 2001). However, learners were de-motivated to learn and failed in other subjects that were presented in Amharic and English. This situation resembled the AACA setting, because what learners were learning was not aligned to the Gamo ethnic culture. C2P1 explained this problem as follows:

\begin{abstract}
As a matter of chance I had the opportunity to teach children who come from households of the Gamo ethnic group, and they learn the subjects in the name of the Ethiopian culture. Among the subjects they learn is a subject called Aesthetics, which integrates the three subjects: Music, Sport and Art together. These integrated subjects emphasise teaching students through play about their environment and the culture of the ethnic group from which they descend. Unfortunately, you do not find anything and any topic about the Gamo culture in this subject.
\end{abstract}

The learners' situation was complicated by instances where the Gamo learners from the countryside schooled in AACA. While those born and brought up in the AACA could easily learn through Amharic and achieve good results, learners from the Gamo ethnic group, who came from the countryside, experienced difficulty in communicating in Amharic and did not understand the subjects that were taught. The non-Gamo teachers also could not do well pedagogically with the Gamo learners as they (the teachers) could not follow the Gamotso language while, on the other hand, the Gamo learners could not understand the Amharic language. These learners became passive in class as a result.

C2P2 related the problem that this state of affairs caused even at home when the Gamo parents had to help their children understand certain concepts:

For example, there may be concepts which are difficult for the students to understand in class, and if they want clarification on the concepts from their parents/guardians at home, the parents/guardians could not explain it because they do not know the concepts due to cultural difference between school education and the ethnic culture.

In GGZ, however, learners were aware of their Gamo identity, language, culture and history to those of others and thus spoke their own language openly and studied the school material in their own language. The observation data also revealed that the use of the Gamotso language in communication, singing and performing the Gamo cultural songs and dances freely, showed learners' pride in their culture in keeping with the literature (Banks, 2006; Bennett, 2011). However, the use of Amharic as medium of communication outside the classroom and the working language in office and 
on the school premises, demonstrated the inferiority attached to their language. This again coincided with the situation in AACA where learners, who came from the Gamo households, showed a confused identity due to the influence of the Amhara-based curriculum. They considered the school world as a better one compared to their community. They were embarrassed by their Gamotso identity, language, food and clothes. This embarrassment emanated from the fact that their culture and language did not feature in the curriculum they received. C2P3 narrated her personal experience in this regard:

Both the members of the Gamo ethnic group and the other ethnic groups do not see the Gamo culture as equal with others. I had the personal experience as a teacher, namely that when I tried to speak to a student in the classroom in the Gamotso language, the child brought his parents to school, and I was warned not to speak the language in class again. The parents feared that their child would be despised and mocked by the other students if he speaks the Gamotso language.

In GGZ C1P2 found an existence of alignment between the knowledge, skills and attitudes learners acquired from the curriculum and the community. He actually blamed the teachers for not implementing the intentions of the curriculum. To the contrary C1P1 and C1P3 indicated the non-alignment between these aspects, unlike the observations and review of the curriculum materials, which revealed some degree of alignment. The level of alignment varied in respect of the curriculum material, which was compiled by means of translation, and the material which was directly prepared by the Zone's Education Department.

\subsection{Problems that entangled the primary education of the Gamo ethnic group during former regimes}

A few problems were communicated through the findings. The curriculum during former regimes did not give recognition to ethnic diversity. The dominant rhetoric was about Ethiopianness, unity and a unitary state. As a result, the majority of Gamos were made to consider everything Gamo worthless and adopted the culture and values of the dominant Amhara ethnic group. At the root of the problem lies the issue of language. The Amharic language was considered as the only language with a written script or alphabet and viable in education with a slight exception in GGZ. Other languages were generally discouraged in education and communication. The schools, particularly in AACA, imposed the Amharic language on the Gamo learners whether they knew or did not know the Amharic language. The Gamo learners were made to feel ashamed of their traditional food and drink, but were insulted and called kurkuffa - eaters and drinkers of skimmed milk or arera. In expressing his personal experience, C1E2 said:

I was one of the individuals who tasted the bitterness of the system, and we suffered a lot. You speak, play and tell a joke in your vernacular language as a kid, and using that language was seen as shameful. Even I suspected that most of the teachers who promoted the superiority of Amharic were not Amharas. Most of the teachers were Oromos, but they compelled us to speak Amharic.

A problem of disparity was experienced when attempts were made to adopt an impartial approach to the curriculum. Irrelevance also manifested through non-relatedness of the education to the political, social and economic development levels of the ethnic groups. Yet another problem was the limited community and stakeholder participation in the education system, which hampered the proper identification of the context of the ethnic groups for consideration in the curriculum and pedagogy. This manifested in the failure of the curriculum of both the rural and city settings to properly reflect the culture and heritage of the Gamo ethnic group emanates from the curriculum development process, which was non-participatory. As Vilakazi (1999) indicated, educated Africans are alienated from the mass base of African society and culture, whereas the ordinary "uneducated" Africans become reservoirs of indigenous knowledge.

\subsection{Suggestions for making the curriculum and the pedagogy culturally responsive}

The participants from GGZ and AACA suggested numerous measures to make the primary first-cycle curriculum responsive to the culture and heritage of the Gamo ethnic group. These are:

- develop the curriculum from the culture and deliver it through culture-conscious teachers, well-versed with the culture, to encourage learner participation and performance;

- collect heritage material and traditional practices in places like school centres and cultural centres at woreda, kebele and gote;

- infuse learning through mother tongue instruction and use the Gamotso language in government offices as the 
work language;

- publish a dictionary of the Gamotso language and prepare reference material to enrich the curriculum;

- incorporate detailed explanations about the cultural artefacts and their pictures and traditions in the curriculum;

- include the Gamo culture in subjects like Environmental Science, History and Aesthetics.

- conduct periodic studies on the culture and heritage of the ethnic group, down to the grassroots level, and involve local people;

- conduct periodic curriculum reviews based on the research findings and the feedback received on the evaluation of the textbooks;

- align the curriculum content to the traditional lives, social structures and perspectives of the community;

- make the curriculum development process a participatory process; include Gamo experts who know their culture well;

- allocate money for research and give due regard to the findings and feedback to back up the independent initiatives of the teacher;

- provide ample training for teachers on the use of culturally responsive pedagogy;

- use teachers who belong to the Gamo ethnic group in the teaching of children from this ethnic group;

- allow all the sector offices to conduct their day-to-day activities in the ethnic group's language;

- conduct an awareness creation campaign to convince learners, parents and administrative bodies of the value of incorporating culture and heritage in the curriculum; and

- give due attention to the hidden curriculum at school to avert the wrong message being communicated on the school premises about language.

The ontological position of this study is that it is imperative to make room for the voices, of those investigated, to be heard (Guba \& Lincoln, 1994), because the true knowledge of the principles and patterns of the civilization of culture remain with ordinary and "uneducated" members, especially those in rural areas. Vilakazi (1999) recommends the involvement of non-certificated men and women in the construction of the high culture of Africa. Thus, the participants in this study forwarded their suggestions, which have been consolidated in the list above.

\section{Conclusions and Recommendations}

The primary first-cycle curriculum for the Gamo ethnic group in GGZ is only partially responsive to the culture and values of this ethnic group, while the curriculum of the AACA almost completely ignored the Gamo culture and values. The failure of the curriculum, as stated above, of both the rural and city settings to properly reflect the culture and heritage of the Gamo ethnic group emanates from the curriculum development process, which is impartial, non-participatory, not grounded on research and non-responsive to the socio-cultural and structural context of the Gamo ethnic group. The findings teach us that learners learn best, become highly motivated and show good academic achievement when the curriculum and pedagogy are culturally relevant. In GGZ learners were highly motivated to learn and scored higher grades in the subjects taught in the Gamotso language. In the AACA the motivation and academic achievement of learners who were born and raised in the city was very good, but not for learners who came from the countryside. Teachers in both settings tried to use different strategies, which were consistent with culturally relevant pedagogy.

The curriculum planning and implementation processes for the Gamo ethnic group in both rural and city settings could be culturally responsive, if a "stand-alone" indigenisation approach is considered. This approach proposes that the curriculum be based on indigenous foundations, theories, principles and ideas derived from the culture, followed by a blended approach that allows for intercultural dialogue. The suggestions contributed by the participants of this study in 4.6, align with the indigenisation approach that we suggest. Thus, we feel strongly that these suggestions should be considered in the development of a model for the indigenisation of the curriculum for the Gamo ethnic group.

\section{References}

Amare, A. (2009a). From knowledge acquisition to knowledge application: the case of curriculum inquiry in Ethiopia. Paper presented at The 1st International Conference on Educational Research for Development. Addis Ababa University, Addis Ababa.

Amare, A. (2009b). Higher education curriculum relevance and educational inputs. Addis Ababa: FSS.

Banks, J. (2006). Cultural diversity and education: foundations, curriculum and teaching (5th ed.). San Francisco: Pearson Education, Inc.

Banks, J. \& Banks, C. (2010). Multicultural education: issues and perspectives (7th ed.). New York: Wiley \& Sons, Inc.

Bennett, C. I. (2011). Comprehensive multicultural education: theory and practice (7th ed). Boston: Pearson Education, Inc.

Blyden, E. W. (1969). African life and customs. London: African Publication Society.

Bogdan, R. C. \& Biklen, S. K. (2007). Qualitative research in education: an introduction to theories and methods (5th ed). Boston, MA: Pearson Education, Inc. Cornbleth, C. (1990). Curriculum in context. London: The Flamer Press. 
Creswell, J. (2009). Research design: qualitative, quantitative, and mixed methods approaches (2nd ed.). Thousand Oaks: SAGE Publications, Inc.

CSA (2008). Summary and Statistical Report of the 2007 Population and Housing Census Results. Addis Ababa: UNFPA.

Dei, G. (2008). Possibilities in African schooling and education. In Dlamini, S. (ed.). New directions in African education: challenges and possibilities. Calgary: University of Calgary Press.

De Lissovoy, N. (2008). Power, crisis, and education for liberation: rethinking critical pedagogy. New York: Palgrave Macmillan Ltd.

Denzin, N. K. \& Lincoln, Y. S. (2005). Introduction. In Denzin, N. K. \& Lincoln, Y. S. (eds.). The Sage handbook of qualitative research (3rd ed.). Thousand Oaks, CA: Sage.

Ferguson, K. M. (2005). Beyond indigenization and reconceptualization: towards a global, multidirectional model of technology transfer. International Social Work, 48(5), 1-17.

Gay, G. (2000). Culturally responsive teaching: theory, research and practice. New York: Teachers College Press.

Gay, G. (2001). Preparing for culturally responsive teaching. Journal of Teacher Education, 53(2), 106-116.

Girma, M. (2012). Cultural politics and education in Ethiopia: a search for a viable indigenous legend. Journal of Politics and Law, 5(1), 117-125.

Gray, M. (2010). Indigenization in a globalizing world: A response to Yunong and Xiong. International Social Work, 53(1), 115-127.

Guba, E. G. \& Lincoln, Y. S. (1994). Competing paradigms in qualitative research. In Denzin, N. K. \& Lincoln, Y. S. (eds). Handbook of qualitative research. (1st ed.). Thousand Oaks, CA: Sage.

Gumbo, M. T. (2001). Multicultural education and its politics. South African Journal of Education, 1(4), 233-241.

Habtu, A. (2003). Ethnic federalism in Ethiopia. Paper presented at the Second EAF International Symposium on Contemporary Development Issues. Addis Ababa, Ethiopia.

Hawi, H. (2005). A search for an alternative Afro-centric development theory. Retrieved April 4, 2008 from www.codesria.org/Links/conferences/ general_assembly11/papers/hawi.pdf

Ismailova, B. (2004). Curriculum reform in post-Soviet Kyrgyzstan: indigenization of the history curriculum. The Curriculum Journal, 15(3), $247-264$.

Janetius, T., Bekele W. \& Mini T. (2008). Indigenizing knowledge base for consequential education in Ethiopia. Paper presented at the Conference of Dilla University. Dilla, Ethiopia.

Kassam, A. (2002). Ethnotheory, ethnopraxis: ethnodevelopment in the Oromia regional state of Ethiopia. In Sillitoe, P., Bicker, A. \& Pottier, J. (eds.). Participating in development: approaches to indigenous knowledge. London: Routledge.

Kincheloe, J. L. (2006). How did this happen? The right-wing politics of knowledge and education. In Steinberg, S. R. \& Kincheloe, J. L. (eds). What you don't know about schools. New York: Palgrave Macmillan.

Kincheloe, J. L. (2008). Knowledge and critical pedagogy: an introduction. Montreal: Springer.

Ladson-Billings, G. (1995). Towards a theory of culturally relevant pedagogy. American Educational Research Journal, 32(3), 465-491.

Lovise, A. (2011). The politics of ethnicity in Ethiopia: actors, power and mobilisation under ethnic federalism. Danvers, MA: Koninklijke Brill NV.

Marcus, H. G. (1994). A history of Ethiopia. Berkeley: University of California Press.

Messay, K. (2004). Africa's quest for a philosophy of decolonization. Amsterdam-New York: Rodopi.

Mkapa, B. (2004). Introduction: local pathways to global development. In Woytek, R., Shroff-Mehta, P. \& Mohan, P. (eds.). Indigenous knowledge: local pathways to global development. Washington D.C.: The Africa Region's Knowledge and Learning Group.

MOE. (2010). Education Sector Development Program IV: Program Action Plan. Addis Ababa: Ministry of Education.

Patton, M. (2002). Qualitative research and evaluation methods (3rd ed.). Thousand Oaks, California: Sage Publications Inc.

Pe-Pua, R. (2006). From decolonizing psychology to the development of a cross-indigenous perspective in methodology: the Philippine experience. In Kim, U., Yang, K. \& Hwang, K. (eds.). Indigenous and Cultural Psychology. Springer Media, Inc.: New York.

Rabaka, R. (2009). Africana critical theory: reconstructing the black radical tradition, from W. E. B. Du Bois and C. L. R. James to Frantz Fanon and Amilcar Cabral. Plymouth: Lexington Books.

Roschanski, H. (2007). Deprived children and education: Ethiopia. Amsterdam: IREWOC.

Salia-Bao, K. (1989). Curriculum development and African culture. London: Edward Arnold.

Shibanda, G. (2006). University perspectives in African indigenous knowledge management. A paper presented at the World Library and Information Congress: $72^{\text {nd }}$ IFLA General Conference and Council. Seoul, Korea. Retrieved October 172012 from www.ifla.org/IV/ifla72/index.htm

Shiundu, J. \& Omulando, S. (1992). Curriculum theory and practice in Kenya. Nairobi: Oxford University Press.

Shizha, E. (2005). Reclaiming our memories: the education dilemma in postcolonial African school curricula. In Abdi, A. \& Cleghorn, A. (eds.). Issues in African education: sociological perspectives. New York: Palgrave Macmillan.

Shizha, E. (2006). Legitimising indigenous knowledge in Zimbabwe: a theoretical analysis of postcolonial school knowledge and its colonial legacy. Journal of Contemporary Issues in Education, 1(1), 20-35.

Shizha, E. (2007). Critical analysis of problems encountered in incorporating indigenous knowledge in science teaching by primary school teachers in Zimbabwe. The Alberta Journal of Educational Research, 53(3), 302-319.

Sinha, D. (1997). Indigenizing psychology. In Berry, J., Poortinga, Y. \& Pandey, J. (eds.). Handbook of cross-cultural psychology: theory and method, Vol. 1. ( $2^{\text {nd }}$ ed). Boston: Allyn and Bacon.

Sleeter, C. E. (2005). Un-standardizing curriculum: multicultural teaching in the standards-based classroom. New York: Columbia University.

Solomon, A. (2008). Policy formulation, curriculum development and implementation in Ethiopia. Addis Ababa: The Book Centre of Addis Ababa University.

Tedla, E. (1992). Indigenous African education as a means for understanding the fullness of life: Amara traditional education. Journal of Black Studies, $23(1), 7-26$.

Tedla, E. (1995). Sankofa: African thought and education. New York: Peter Lang.

Tekeste, N. (2006). Education in Ethiopia: from crisis to the brink of collapse. Stockholm: Nordiska Afrikainstituet.

Teklehaimanot, H. (1999). The cultural foundation of education in Ethiopia. IER Flambeau, 7(1), 1-10.

Tomaselli, K. \& Shepperson, A. (1999). Media studies and practice reborn: recovering African experiences. In Makgoba, M. W. (ed). African renaissance: the new struggle. Cape Town: Mafube Publishers Limited.

UNESCO. (2009). Investing in cultural diversity and intercultural dialogue. Paris: UNESCO.

Vilakazi, H. W. (1999). The problem of African universities. In Makgoba, M. W. (ed.). African renaissance: the new struggle. Cape Town: Mafube Publishers Limited.

Walton, R. \& Abo El Nasr, M. (1988). Indigenization and authentization in terms of social work in Egypt. International Social Work, 31(2), 135-144.

Woube, K. (2004). The need for analyzing culture in planning curriculum. IER Flambeau, 11(2), 13-32.

Yin, R. (2009). Case study research: design and methods ( $4^{\text {th }}$ ed). Thousand Oaks, CA: Sage.

Yishak, D. \& Gumbo, M. (2012). Indigenizing the school curriculum: an alternative approach for ensuring relevance to the context. Indilinga - African Journal of Indigenous Knowledge Systems, 11(2), 179-193.

Yunong, H. \& Xiong, Z. (2008). A reflection on the indigenization discourse in social work. International Social Work, 51(5), 611-622. 